\section{COELIAC DISEASE*}

\author{
BY
}

\begin{abstract}
WILFRID SHELDON, M.D., F.R.C.P.
Physician to the Hospital for Sick Children, Great Ormond Street; Physician in Charge, Children's Department, King's College Hospital
\end{abstract}

Few conditions in childhood have maintained their challenge more persistently than has coeliac disease. A satisfactory explanation of the fault that underlies this malady has yet to be made ; the course is long, usually extending over years ; treatment is apt to be a prolonged trial to all concerned; and the eventual outcome is by no means invariably satisfactory, for, apart from a mortality rate of roughly $10 \%$, in those who survive some permanent dwarfing of height may be a legacy, and in a few cases steatorrhoea may continue into adult life.

\section{Coeliac Syndrome}

Coeliac disease is not the only cause of steatorrhoea in young children. Occasionally if tuberculous infection of the mesenteric glands is sufficiently widespread mechanical interference with fat absorption may lead to steatorrhoea, the stools closely resembling those of coeliac disease, and in addition there is likely to be both wasting and some degree of abdominal distension. The history, the presence of palpable gland masses in the abdomen, the response to tuberculin skin tests, and perhaps the evidence of calcification in the mesenteric glands in the $x$-ray film will, however, facilitate the differential diagnosis.

Steatorrhoea with diarrhoea and some abdominal distension may also be associated with infection by Lamblia intestinalis. The degree of wasting never reaches that of severe coeliac disease, and examination of the stools for Lamblia cysts will distinguish the two conditions. There is also a group of children who exhibit steatorrhoea as an accompaniment to severe and prolonged infection, and in such the character of the stools and the degree of wasting may simulate coeliac disease. As a rule, however, a reduction in dietary fat quickly checks the steatorrhoea, and when once the chronic infective stage is passed the fat in the diet can be restored within a few weeks.

Lastly, the clinical state that results from fibrocystic disease of the pancreas mimics very closely that of coeliac disease, for steatorrhoea, severe malnutrition, and abdominal distension are common to both, yet the two conditions are in fact unrelated, and on clinical grounds alone it is usually possible to distinguish them.

The several conditions enumerated above share in common the symptoms of fatty stools, wasting, and abdominal distension, and it has become fashionable in paediatric parlance and literature to speak of young children who exhibit them as suffering from the "coeliac syndrome." This implies that coeliac disease is not a separate clinical entity but a state compounded of a group of symptoms which can be broken down into various causes. It can, however, be contended that by clinical investigation and laboratory aids it is possible to separate the other causes and to leave a residue of children whose illness conforms to the original clinical concept of coeliac disease. Although it must be confessed that coeliac disease remains an idiopathic condition, the retention of the name is advantageous if only to avoid confusion with other causes of steatorrhoea in young children-a confusion which the term "coeliac syndrome" encourages.

* Read in opening a discussion in the Section of Radiology at the Annual Meeting of the. British Medical Association, Cambridge, 1948.

\section{Fibrocystic Disease of the Pancreas}

This is the illness most easily confounded with coeliac disease, and the two conditions may therefore be contrasted. The identification of pancreatic fibrosis may be said to date from 1938, when Andersen reviewed the literature and collected a group of 49 cases. Since then the disease has become widely recognized and the literature on the subject has rapidly expanded.

In contrast to coeliac disease, pancreatic fibrosis has a definite tendency to affect more than one member of a family; indeed, a familial incidence occurs in roughly a quarter of the cases. It is rare for coeliac disease to do this, and for more than one child of a family to be affected must be regarded as probably fortuitous. The age of onset is notably different, for, while coeliac children develop normally for several months up to a year or more after birth, those with pancreatic fibrosis present symptoms from birth, and the underlying pathological process probably originates in most cases during intrauterine life. The effect of the disease is to reduce, often to vanishing point, the external secretion of the pancreas, and when this occurs before birth the meconium may be of such stiff consistency as to give rise to symptoms of intestinal obstruction within a few days of birth, often with fatal results. The name "meconium ileus" aptly describes this state of affairs. Among the 49 cases of pancreatic fibrosis collected by Andersen there were two instances of meconium ileus, the first having been described by Landsteiner in 1905. In addition, two infants showed intestinal atresia.

Another point of contrast lies in the state of the appetite. Coeliac children have a notoriously fickle appetite, but infants with pancreatic fibrosis have a good, even voracious appetite, although in spite of this they persistently fail to thrive, and by the time they reach the age of 1 year may be several pounds below their expected weight.

Malnutrition and abdominal distension are notable features in the pancreatic group, becoming apparent within a few months of birth, while the stools tend to be large, loose, pale, and decidedly offensive. These symptoms also characterize coeliac disease, and it can be readily understood that if a child with pancreatic fibrosis is not seen until the age of 1 year or more these features may at first lead to confusion with coeliac disease, although a careful history should suggest the correct diagnosis. A small point, but of some help to those with experience of both conditions, is that the odour of the stools in pancreatic fibrosis is even more repellent than that of the coeliac stool, probably by virtue of the fact that while both stools contain an excess of fat and starch the pancreatic stool also contains unabsorbed and decomposed dietary protein.

In both conditions a barium meal shows a loss of the normal feathery pattern of the small intestine, which is replaced by a clumping of the barium into separate masses of varying size. The rate of passage of the barium to the caecum tends to be accelerated.

\section{Pulmonary Complications}

There is, however, a further point of contrast between coeliac disease and pancreatic fibrosis, for in the latter condition sooner or later, and often within a few months of birth, chronic pulmonary suppuration develops. There may be a history of one or more attacks of bronchopneumonia in infancy from which recovery has been all too tardy; in others the lung infection develops without a definite history of acute illness, but eventually the clinical picture is that of bronchiectasis, with production of purulent sputum, breathlessness, cyanosis, and perhaps fingerclubbing. Once this state has developed, the previously 
good appetite is likely to be lost, treatment of the lung condition is thoroughly unsatisfactory, and the state of the child steadily deteriorates until in a matter of months or a few years the disease in the chest kills the patient.

Various reasons have been put forward to account for the proclivity to pulmonary complications. These infants have a flat vitamin-A absorption curve, and lack of this vitamin has been supposed to contribute to the liability to respiratory infection; but coeliac children also have a flat vitamin-A absorption curve (May et al., 1942), which in both conditions is ascribed to failure to absorb fat, and yet gross lung disease is not particularly encountered in the coeliac child. It is more probable that the respiratory troubles of the child with pancreatic fibrosis are in the main due to congenital cystic disease of the lungs, the lesions in lung and pancreas being due to a common foetal pathology.

Respiratory infection is so prominent in children with pancreatic fibrosis that it seems probable that, prior to Andersen's article in 1938, children with this condition were regarded as suffering primarily from bronchiectasis or chronic lung infection rather than that they were confused with cases of coeliac disease.

\section{Laboratory Findings}

In addition to the clinical distinction between the two diseases, laboratory investigation also reveals decisive differences. Thus Farber et al. (1943), in 150 analyses of the pancreatic enzymes obtained from the duodenal contents of infants and children, showed that trypsin, lipase, and amylase were produced in normal amounts by coeliac children but were either absent or very much reduced in children with pancreatic fibrosis. Herein lies an important method of differentiation. As regards lipase, the technical difficulties in its estimation and the wide range of values obtained from control cases prevent the assay of this enzyme from being used for the routine confirmation of the diagnosis of pancreatic fibrosis. As to amylase, its very low production by infants under 6 months of age and the fact that amylase from the saliva may be recovered from the duodenum, particularly when gastric hypochlorhydria is present as often happens in coeliac children, make the evaluation of this enzyme unsuitable as a diagnostic aid. The presence of trypsin is, however, easy to estimate by its digestive effect on a standard solution of gelatin, and at the present time lack of trypsin in the duodenal juice is the criterion upon which a diagnosis of pancreatic fibrosis is acceptable.

Further evidence of failure to digest protein has been furnished by West et al. (1946), who showed that there is a normal blood amino-nitrogen curve following ingestion of such proteins as casein and gelatin. Infants with coeliac disease have a normal curve; those with pancreatic fibrosis have a flat curve after ingestion of either casein or gelatin, although the curve is normal after ingestion of casein hydrolysate, and a combination of pancreatin with casein tends to restore the curve towards normal.

The advantage of pancreatin in the treatment of pancreatic fibrosis was also pointed out by Shohl et al. (1943), who showed that this preparation tended to lower the nitrogen content of the stools but considered that it did not benefit fat digestion, although Andersen (1945) contended that it reduced both the total faecal excretion and the amount of faecal fat. She regards an optimum diet for children with this disorder to be one in which protein provides $25 \%$ of the calories, the fact content is low, and carbohydrate is given mainly as sugar, with small amounts of starch for older children. There is clearly an advantage in making casein hydrolysate a regular feature of the diet, and even in infancy not less than $60 \mathrm{gr}$. $(4 \mathrm{~g}$.) of pancreatin (enteric-coated) should be given daily with the meals.

Apart from dietetic management, treatment of pancreatic fibrosis has also to contend with infection in the lungs. This complication affects the prognosis so adversely that every attempt must be made to prevent its occurrence. Good hygienic surroundings and the avoidance so far as possible of droplet infections are obvious measures. It is as yet too soon to assess the prophylactic value of oral penicillin.

\section{Clinical Manifestations of Coeliac Disease}

These are too well known to require reiteration, but a review will be given of some commonly held views in the light of recent investigations. Of the many excellent and authoritative clinical descriptions tribute must be paid to Gee's original article in 1888 on the coeliac affection, to Still's Lumleian Lectures delivered in 1918, and to Parsons's Rachford Memorial Lectures of 1932. Still drew attention to the small size of the liver as a common characteristic, and although later authors seldom refer to this feature it is a clinical detail of some diagnostic value owing to its constancy.

Parsons completely summarized our knowledge of coeliac disease up to 1932, and at that date the condition was generally regarded as a well-defined entity. The onset is usually between 6 and 18 months of age (see Chart), and

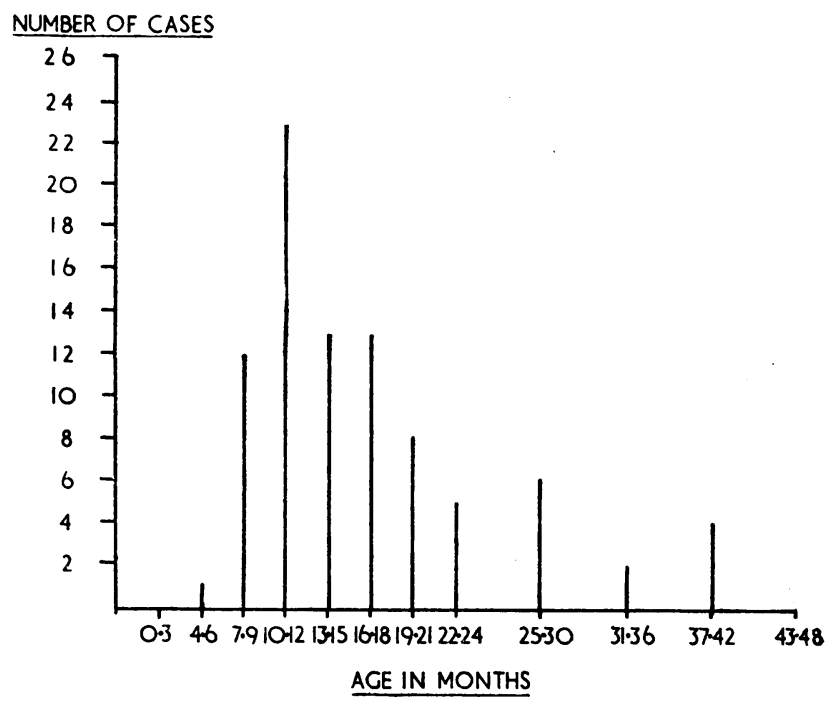

Chart showing age of onset in 87 cases of coeliac disease.

the clinical picture is characterized by a group of symptoms the most prominent of which consist of severe wasting, a striking degree of abdominal distension, and the passage of large, unformed, pale offensive motions containing an excessive quantity of fat, mostly in the form of fatty acids and soaps.

Although it has for long been generally appreciated that starchy foods are badly borne, and indeed Howland in 1921 regarded a failure to manage carbohydrate as the primary trouble, the view that failure to absorb the products of digestion of fat is the principal fault in coeliac disease, other digestive and absorptive errors being of a secondary nature, has for many years had popular support. This view has largely dictated the lines of treatment, of which the first principle has been a severe curtailment of dietary fat. The effect of this has been to diminish the amount of fat excreted in the stools, and the maintenance of a low faecal-fat excretion has been regarded as advantageous. A reduction of starchy food has also proved to be necessary in order to avoid troublesome diarrhoea. 
Consequently the dietetic management of coeliac disease has consisted of giving in the first place an almost purely protein diet, followed by the cautious addition of starcha stage usually difficult to establish because of the liability to diarrhoea. The final stage has been the reintroduction of fat. These stages have always taken months, and sometimes even years, to attain. Throughout treatment the addition of vitamin concentrates has largely abolished the development of deficiency complications, which were at one time a common feature of coeliac disease.

\section{Aetiology}

The view that coeliac disease itself, apart from its complications, might be in part a deficiency disorder, has been put forward by May et al. (1942), who claimed that the intramuscular administration of crude liver and vitamin $B$ restored the vitamin-A curve to normal and improved the glucose-absorption curve. These substances were much less effective by mouth, suggesting that their absorption from the intestine was defective. In this country Paterson et al. (1944) reported favourably on this method of treatment, but others have been less successful, and as daily intramuscular injections are undoubtedly irksome to the children this form of therapy has not gained popularity.

There are certain points in the history of coeliac disease which should be borne in mind when seeking for an adequate aetiology. For example, it has already been pointed out that in the early months of life, before the illness develops, the infants thrive satisfactorily on a diet of either breast milk or cows' milk, and clearly at that stage the digestion and absorption of the various elements of milk present no difficulty. As there is no starch in milk, amylase is not required by the young infant, but both trypsin and lipase must be present. If failure to utilize fat is eventually to appear, there is no hint of this in the early months, nor does the history of the feeding of coeliac children in early infancy depart in any respect from the routine methods applied to infants in general.

The age of onset of coeliac disease in most cases coincides roughly with the stage when the diet is expanding from milk to mixed feeding. This means the introduction into the diet of new types of protein and fresh forms of animal and vegetable fat, but the greatest change at this age is the addition to the diet of starch in rapidly increasing amount. In this connexion it is of interest that analyses of duodenal juice (Farber et al., 1943 ; Andersen, 1945) have shown that while trypsin and lipase are present from birth the amount of amylase is negligible in the first three months, but then gradually rises to reach a maximum at about the age of 3 years.

\section{Fat Intake}

The view that coeliac children fail to absorb fat is based upon the excretion of excessive amounts of fat in the stools, and the flat vitamin- $A$ absorption curve has been regarded as corroborative evidence of this view. It is, however, open to argument whether the results of faecal-fat analyses justify a sharp reduction of the dietary fat. Fat balances show that in health at least 90 to $95 \%$ of dietary fat is absorbed, and at the same time stool analyses in healthy infants and children show that fat accounts for from onequarter to one-third of the dried stool. Even if the amount of faecal fat were doubled (as often occurs in coeliac disease) it would still be possible for at least three-quarters of the ingested fat to be absorbed ; therefore, unless it can be shown that the steatorrhoea of the coeliac child is harmful and must at all costs be reduced, it would seem illogical to deny them fat in their diet.

The striking degree of abdominal distension in the coeliac child can hardly be due to the high faecal-fat excretion, for in young infants fed on a diet containing more fat than they can tolerate gross abdominal distension is not a clinical feature, nor does it accompany the steatorrhoea associated with liver damage in older children. The distension may be due to some extent to loss of muscle tone, but in the main results from excessive fermentation of carbohydrate, and the diarrhoea to which these children are so notoriously prone is due to carbohydrate fermentation rather than to steatorrhoea.

For the above reasons, while accepting the fact that coeliac children pass an excessive amount of fat in their stools, the view that fat in their diet should be severely reduced is difficult to maintain ; indeed, the evidence would suggest that attention ought to be directed primarily towards their difficulty with starches. This attitude has been developed by Andersen (1947), who considers that the steatorrhoea of coeliac children is not part of the basic process but that the long-recognized clinical intolerance towards starch is of primary importance. She contends that the production of pancreatic amylase is deficient, that feeding of starch leads to excessive excretion of faecal starch in extracellular form, and that a good clinical response follows the elimination of starch from the diet, which should otherwise contain a normal proportion of fat and a relatively high amount of protein. In passing, it is of interest to note that Gee, in his original description, recommended giving good fresh butter and even advised a trial of cream.

The whole question of fat absorption in coeliac children has become further complicated by the new views on the physiology of fat absorption put forward by Frazer (1943). $\mathrm{He}$ regards as untenable the older view that all fat requires breaking down to fatty acids and glycerol before being absorbed into the intestinal cell, where it is resynthesized before passing into the lacteal system. He has demonstrated that a proportion of the dietary fat is finely emulsified in the upper intestine and is absorbed as fat particles into the lacteals, then passing via the thoracic duct to the various fat depots in the body; the proportion of dietary fat which escapes this process is digested to fatty acids and glycerol, these substances being absorbed into the portal system and passing to the liver.

If Frazer's views are accepted, it remains to determine which system of fat absorption is at fault in coeliac children or whether both are defective. In any case, for the reasons given above, the estimation of total faecal fat and its division into split and unsplit proportions loses much of its significance as a guide to treatment, although it may tetain some diagnostic importance. Clearly a knowledge of the amount of dietary fat which a coeliac child absorbs is of far greater value than estimations merely of faecal-fat excretion, but for this information fat balances must be carried out. As a guide to treatment these should replace the customary estimations of faecal fat.

Mention must also be made of the flat oral-glucose absorption curve which is so characteristic of coeliac disease. Intravenous glucose given to coeliac children is metabolized at a normal rate and the flat oral curve is generally taken to indicate difficulty in the absorption of glucose from the intestine. This view has been attacked by Emery (1947). He has shown that, while in coeliac children the fall in blood sugar induced by insulin follows the usual pattern, the subsequent return to a normal level fails to materialize, although it can be restored by giving glucose orally. The effect of adrenaline on the blood-sugar level gives a smaller and slower response in coeliac children than in normal controls, although if glucose is given by mouth at the same time as the injection of adrenaline a normal response ensues. For these reasons he argues that coeliac children absorb glucose normally and utilize it 
normally; he explains the flat oral-glucose curve as being due to lack of available glycogen in the body, with the result that oral glucose is utilized by the liver as fast as it enters the portal system.

\section{Summary}

It is contended that coeliac disease maintains to-day its position as a clinical entity, and can be distinguished from fibrocystic disease of the pancreas and from the other causes of steatorrhoea in childhood. To group all these conditions under the term "coeliac syndrome" is confusing. The facts regarding excessive faecal-fat excretion and the flat oral-glucose absorption curve in coeliac children are not disputed, but their significance requires reconsideration.

The view that coeliac disease is due to a defect in the absorption mechanism of the intestine does not as yet rest on a sure foundation. It may still remain to identify the varying clinical conditions that result from a failure to produce any one of the several enzymes required for complete digestion.

\section{REFERENCES}

Andersen, D. H. (1938). Amer. J. Dis. Child., 56, 344.

(1945). Ibid., 69, 221.

(1947). J. Pediat., 30, 564.

Emery, J. L. (1947). Arch. Dis. Childh., 22, 41.

Farber, S., Shwachman, H., and Maddock, C. L. (1943). J. clin. Invest., $22,827$.

Frazer, A. C. (1943). J. Physiol., 102, 306.

Gee, S. (1888). St. Barts Hosp. Rep., 24, 17.

Howland, J. (1921). Trans. Amer. ped. Soc., 33, 11.

Landsteiner, K. (1905). Zbl. allg. Path. path. Anat., 16, 903.

May, C. D., McCreary, J. F., and Blackfan, K. D. (1942). J. Pediat., 21, 289

Parsons, L. G. (1932). Amer. J. Dis. Child., 43, 1293.

Paterson, D., Pierce, M., and Peck, E (1944). Arch. Dis. Childh.,

Shohl, A. T., May, C. D., and Shwachman, H (1943). J. Pediat., 23, 267.

Still, G. F. (1918). Lancet, 2, 163, 193, 227. West, C. D. D., Wilson, J. L., and Eyles, R. (1946). Amer. J. Dis.
Child., 72, 251.

\section{A STUDY OF BREAST-FEEDING IN A MINING TOWN}

BY

\section{ENID L. HUGHES, M.B., B.S., M.Sc., D.C.H.}

Assistant County School Medical Officer, Northumberland

This work is a study of the incidence of breast-feeding during the five war years, 1941-5, in Newbiggin-by-the-Sea, a small town on the coast of Northumberland, and continues a similar study of the babies born in 1940 (Hughes, 1942).

Many previous surveys of this problem have been weakened by the fact that they cover only part of the community. This is an attempt to study a whole community. Newbiggin lends itself to such an inquiry, as there is a very large attendance at the infant welfare clinic, so that a picture has been obtained of nearly $90 \%$ of the infant population. There was no social distinction at the welfare. The curate's wife and the doctor's daughter brought their babies, as did the miners' wives and local " ne'er-do-weels."

\section{The Community Studied}

Newbiggin-by-the-Sea-once a fishing village-is now a small town with a population of just over 9,000, mostly concerned in mining. The war did not hit the village very hard. There was frequent passage of enemy planes, and one stick of bombs was dropped (known locally as "Wer blitz"); the population was temporarily swollen in 1943-4 by private evacuees from the South, and in 1942 the call-up began to affect the fathers of the infant population. In $1941,62 \%$ of the fathers of the babies here recorded were miners and $11 \%$ were in the Forces; in $1942,49 \%$ were miners and $25 \%$ were in the Forces ; and in 1945 the figures were $46 \%$ miners and $35 \%$ in the Forces.

There was no real poverty throughout the period studied, but the larger families were perhaps less well catered for than in other places, since there are no school meals in Newbiggin. The miners' canteen was not well patronized, so that in a large family the mother's nutrition was likely to suffer.

An increase in the number of hospital deliveries is very evident over these five years. In 1940 (Hughes, 1942) midwives delivered $77 \%$ of the babies, $11.5 \%$ were doctors' cases, and $11.5 \%$ were born in nursing-homes or hospitals. By 1943 the figures were $71 \%$ midwives' cases and $25 \%$ hospital deliveries. In $194562 \%$ were midwives' cases, $5 \%$ doctors' cases, and $32 \%$ hospital deliveries. This change was mainly due to the difficulty of getting help in the home. Even so, it will be seen that the great majority of deliveries were by midwives.

\section{Present Investigation}

The babies here studied are those born of Newbiggin parents in 1941-5 inclusive and continuing to live there till at least 6 months old. (This excludes the babies dying before the age of 6 months, evacuee babies born elsewhere, and babies whose mothers came to Newbiggin for the birth and moved soon afterwards.) Of the babies thus defined, $89.4 \%$ attended the clinic regularly enough over these five years for details to be recorded of their dates of weaning. The actual numbers are given in Table $I$. (The drop in 1943 is due to my illness and absence from work for several months.) The figures for 1940 , previously published, are included for comparison.

TABLE I.-Proportion of the Infant Population Studied in each Year

\begin{tabular}{|c|c|c|c|}
\hline \multicolumn{2}{|r|}{ Year } & $\begin{array}{l}\text { No. Born and Lived } \\
6 \text { Months }\end{array}$ & No. Included in Records \\
\hline $\begin{array}{l}1940 \\
1941 \\
1942 \\
1943 \\
1944 \\
1945\end{array}$ & $\begin{array}{cc}\because & \cdots \\
\because & \cdots \\
. & \cdots \\
. & \cdots \\
. & \ldots\end{array}$ & $\begin{array}{l}117 \\
114 \\
137 \\
116 \\
146 \\
100\end{array}$ & $\begin{array}{r}112(95 \%) \\
105(92 \%) \\
124(91 \%) \\
98(85 \%) \\
131(90 \%) \\
90(90 \%)\end{array}$ \\
\hline
\end{tabular}

The time of weaning is recorded in Table II, including also the 1940 figures. Figures of those completely breastfed at 3 months are included. Comparison with the percentage weaned by 3 months will give the percentage who had their babies partly on the breast at this age.

TABLE II.-The Incidence of Weaning

\begin{tabular}{|c|c|c|c|c|c|c|c|}
\hline \multirow{2}{*}{\multicolumn{2}{|c|}{ Year }} & \multirow{2}{*}{$\begin{array}{l}\text { No. } \\
\text { Recorded }\end{array}$} & \multicolumn{4}{|c|}{ Percentage Weaned by } & \multirow{2}{*}{$\begin{array}{l}\text { Percentage } \\
\text { Completely } \\
\text { Breast-fed at } \\
3 \text { Months }\end{array}$} \\
\hline & & & $\begin{array}{c}2 \\
\text { Weeks }\end{array}$ & $\begin{array}{c}1 \\
\text { Month }\end{array}$ & $\begin{array}{c}3 \\
\text { Months }\end{array}$ & $\begin{array}{c}6 \\
\text { Months }\end{array}$ & \\
\hline 1940 & . & 112 & 31 & & 57 & & 32 \\
\hline $\begin{array}{l}1941 \\
1942 \\
1943 \\
1944 \\
1945\end{array}$ & $\begin{array}{l}. . \\
\because \\
\cdots\end{array}$ & $\begin{array}{r}105 \\
124 \\
98 \\
131 \\
90\end{array}$ & $\begin{array}{l}32 \\
36 \\
25 \\
23 \\
27\end{array}$ & $\begin{array}{l}40 \\
45 \\
34 \\
37 \\
40\end{array}$ & $\begin{array}{l}67 \\
65 \\
47 \\
57 \\
59\end{array}$ & $\begin{array}{l}81 \\
83 \\
80 \\
83 \\
83\end{array}$ & $\begin{array}{l}30 \\
25 \\
30 \\
30 \\
24\end{array}$ \\
\hline $1941-5$ & . & 548 & 29 & 39.5 & 59 & 82 & 29 \\
\hline
\end{tabular}

This is a very high and maintained proportion of early weanings, and exceeds any other published figures I have seen.

Among those weaned by 2 weeks there is the same proportion of first babies $(47 \%)$ as among the whole number recorded. It is usually stated that babies delivered by midwives are breast-fed more successfully than babies born in hospital. Here, however, $32 \%$ of all the babies delivered by midwives and $20 \%$ of those delivered in hospital were weaned by 2 weeks. 